\title{
Results of an Interlaboratory Comparison of Analytical Methods for quantification of anhydrosugars and biosugars in atmospheric aerosol
}

M. Chiara Pietrogrande* ${ }^{\mathrm{a}}$, Elena Barbaro ${ }^{\mathrm{b}}, \mathrm{M}$. Chiara Bove $^{\mathrm{c}}$, Giuseppe Clauser ${ }^{\mathrm{d}}$, Cristina Colombi ${ }^{\mathrm{e}}$, Lorenza Corbella ${ }^{f}$, Eleonora Cuccia ${ }^{\mathrm{e}}$, Stefano Dalla Torre ${ }^{\mathrm{g}}$, Stefano Decesari ${ }^{\mathrm{h}}$, Paola Fermo ${ }^{\mathrm{f}}$, Andrea Gambaro ${ }^{\mathrm{b}}$, Vorne Gianelle ${ }^{\mathrm{e}}$, Pierina Ielpo, Roberto Larcher, Paolo Lazzeri ${ }^{\mathrm{i}}$, Dario Massabò $^{\mathrm{c}}$, Gerardo Melchionna ${ }^{\mathrm{j}}$, Tiziana Nardin ${ }^{\mathrm{i}}$, Marco Paglione ${ }^{\mathrm{h}}$, Cinzia Perrino ${ }^{\mathrm{g}}$, Paolo Prati ${ }^{\mathrm{c}}$, Marco Visentin ${ }^{\mathrm{a}}$, Nicola Zanca ${ }^{\mathrm{h}}$, Roberta Zangrando ${ }^{1}$

${ }^{a}$ Department of Chemical and Pharmaceutical Sciences, University of Ferrara, Via Fossato di Mortara 17/19 - 44121 Ferrara, Italy

${ }^{\mathbf{b}}$ Department of Environmental Sciences, Informatics \& Statistics, University Ca' Foscari of Venice, Via Torino 155, 30170 Venice Mestre, Italy

${ }^{\mathbf{c}}$ Department of Physics, University of Genoa, Via Dodecaneso, 33, 16146 Genoa, Italy

d Agenzia Provinciale Protezione Ambiente, via Lidorno 1, 38123 Trento, Italy

${ }^{\text {e }}$ ARPA Lombardia, Via I. Rosellini 17, 20124 Milan, Italy

${ }^{\mathbf{f}}$ Department of Chemistry, University of Milan, Via Golgi 19, 20133 Milan, Italy

${ }^{\mathbf{g}}$ National Research Council (CNR) Institute of Atmospheric Pollution Research Rome, Piazza Aldo Moro 7, 00185 Rome, Italy

${ }^{\mathbf{h}}$ National Research Council (CNR) Institute of Atmospheric Sciences and Climate (ISAC), Via Gobetti 101, 40129 Bologna, Italy

${ }^{\mathrm{i}}$ National Research Council (CNR) Water Institute Research - CNR, Viale de Blasio 5, 70132 Bari, Italy.

${ }^{\mathbf{j}}$ Edmund Mach Foundation Research and Innovation Centre, Via Edmund Mach 1, 38010 San Michele all'Adige (TN), Italy

${ }^{\text {k} A R P A ~ P i e m o n t e, ~ V i a ~ S a b a u d i a ~ 165, ~} 10095$ Grugliasco (TO), Italy

${ }^{\mathrm{l}}$ Institute for the Dynamics of Environmental Processes-CNR, Via Torino 155, 30172 VeniceMestre, Italy

*Corresponding Author: Prof. M. Chiara Pietrogrande, email: mpc@unife.it 


\section{Highlights}

- An intercomparison study was performed in 10 Italian laboratories for quantifying sugars in PM.

- Gas and Liquid chromatography and NMR methods were used for analysis of 26 ambient and 3 synthetic PM filters.

- Different separation and detection systems yielded comparable results for most of the samples.

- Low interlaboratory variability (RSD\% from $25 \%$ to $46 \%$ ) and good accuracy ( $\varepsilon \%$ within $\pm 20 \%$ ) were found.

\section{ABSTRACT}

An interlaboratory comparison was performed to evaluate the analytical methods for quantification of anhydrosugars - levoglucosan, mannosan, galactosan - and biosugars - arabitol, glucose and mannitol - in atmospheric aerosol. The performance of 10 laboratories in Italy currently involved in such analyses was investigated on twenty-six PM (particulate matter) ambient filters, three synthetic PM filters and three aqueous standard solutions.

An acceptable interlaboratory variability was found, determined as the mean relative standard deviation (RSD\%) of the results from the participating laboratories, with the mean RSD\% values ranging from $25 \%$ to $46 \%$ and decreasing with increasing sugar concentration. The investigated methods show good accuracy, evaluated as the percentage error $(\varepsilon \%)$ related to mean values, since method biases ranged within $\pm 20 \%$ for most of the analytes measured in the different laboratories. The detailed investigation (ANOVA analysis at $p<0.05$ ) of the contribution of each laboratory to the total variability and the measurement accuracy shows that comparable results are generated by the different methods, despite the great diversity in terms of extraction conditions, chromatographic separation - more recent LC (liquid chromatography) and EC (exchange chromatography) methods compared to more widespread GC (gas chromatography) - and detection systems, namely PAD (pulsed amperometric detection) or mass spectrometry.

\section{Keywords}

Interlaboratory comparison

Analytical methods

Atmospheric aerosol

Biomass burning

Biogenic emissions 


\section{Capsule}

An interlaboratory study evaluated comparability of common analytical methods used to quantify sugars in ambient aerosol filter samples, as relevant markers of biomass burning and biogenic emissions.

\section{INTRODUCTION}

There is a general consensus that emissions from residential wood combustion strongly impact air quality, especially during the winter seasons, when the domestic burning of wood logs, briquettes, chips and pellets represents an important renewable energy source. In fact, biomass combustion in domestic appliances has been demonstrated to contribute significantly to emissions of the total $\mathrm{PM}_{2.5}$ and $\mathrm{PM}_{10}$ and also to contain numerous toxic/carcinogenic components with a potentially high impact on human health (Calvo et al. 2013; Perrone et al. 2013; Xu et al. 2015). Therefore, there are increasing efforts in the monitoring of the contribution of such emissions, that is based on the quantification of the chemical tracers for biomass burning useful to estimate both open and residential biomass combustion to fine particle concentrations. The key tracer is levoglucosan - with minor quantities of its isomers mannosan, galactosan - as primarily produced during biomass combustion as the pyrolytic decomposition product of cellulose and hemicellulose (Calvo et al. 2015; Herich et al. 2014; Kourtchev et al. 2011; Puxbaum et al. 2007).

Despite regulations being needed to increase the incentives to take these compounds into consideration, tools that facilitate accurate monitoring of them are also important. Although several procedures have been applied to analyze sugars in atmospheric aerosol, the absence of a standardized method leaves still open the question of whether results generated by a given method accurately depict the true concentration of each sugar in the aerosol and whether the results from various methods are comparable (Kourtchev et al. 2007; Schkolnik and Rudich 2006; Yttri et al. 2015). Because NIST Standard Reference Materials of Fine Particulate Matter are available only for three anhydrosugars sugars (i.e., SRM2786 e SRM2787) and matrix effects caused by non-target background interferences may lead to the reporting of inaccurate concentrations, interlaboratory comparison studies are the best means to assess the comparability of the reported data on a compound-by-compound basis (Lundstedt et al. 2014; Vanderford et al. 2014; Yttri et al. 2015).

The present paper describes an interlaboratory study with the objective to compare the performance of 10 laboratories for quantifying sugars in ambient aerosol using the most common methods in ongoing research and monitoring efforts, as reported in the scientific literature so far. They are gas chromatographic methods that have been the well-established for many years (Fabbri et al. 2008; 
Hsu et al. 2007; Pashynska et al. 2002; Pietrogrande et al. 2013) and liquid chromatographic methods that were more recently developed and are actually gaining attention (Barbaro et al. 2015; Caseiro et al. 2007; Piazzalunga et al. 2012; Piot et al. 2012; Yttri et al. 2015). The investigated methods differ to a large extent with respect to crucial parameters, such as extraction procedure and derivatization agent, chromatographic separation and detection systems, which are variously combined in the investigated procedures. This adds additional strength to any conclusion to be drawn from the study.

In order to investigate the possible effect of unknown interferences in the complex PM matrix, the study was performed on different sample types, i.e., aqueous standard solutions, synthetic PM filters and PM ambient filters.

\section{EXPERIMENTAL SECTION}

Participating laboratories/Methods. Ten laboratories located in different cities in Italy participated in the current intercomparison exercise. A brief overview of the various analytical methods is given in Table 1 - including information about the instrument used for separation and detection of the analytes, the solvent(s) and experimental condition used for extraction and whether analytes derivatization was applied - and the details on the analytical performance of each method and the quality of quantification standards are presented in the Supplementary Information (Table S1). Most of the participating laboratories used high-performance anion-exchange chromatography (EC), demonstrating that such recent instruments are actually being more widespread employed for analysis of sugars in aqueous extracts. EC systems were coupled with pulsed amperometric detection (EC-PAD) (Piazzalunga et al. 2012) or with mass spectrometric detection (EC-MS) (Barbaro et al. 2015). Another procedure is based on High Performance Liquid Chromatography combined with Mass Spectrometry (HPLC-MS, lab LC-MS) (Piot et al. 2012). Two gas chromatography-mass spectrometry (GC-MS) methods were investigated, as well established methods for separation and quantification of sugars in environmental samples. They make use of solvent extraction followed by derivatization with N,O-bistrimethylsilyltrifluoroacetamide (BSTFA) in combination with trimethylchlorosilane (TCMS) in order to increase the volatility and thermal stability of the molecules and to reduce their surface interactions (Fabbri et al. 2008; Pietrogrande et al. 2013).

Finally, a methodology based on proton nuclear magnetic resonance spectroscopy $\left({ }^{1} \mathrm{H}-\mathrm{NMR}\right)$ was considered, as a very different non-destructive method used for the characterization of organic compounds in many applications and since the last fifteen years even for organic aerosol characterization (lab NMR). It allows direct analysis of samples avoiding separation due to the 
selectivity of the spectroscopic detection provided by specific signals in the spectrum given by organic compounds (Decesari et al. 2006; Paglione et al. 2014.

Samples preparation and shipment. The intercomparison study was performed on different sample types representing gradually more complex matrices in order to investigate the possible contribution of the sample components to the performance of the analytical methods: 1) aqueous standard solutions, 2) synthetic PM filters and 3) PM ambient filters.

Three aqueous standard solutions were prepared with known concentrations of six sugars at three concentration levels (low, medium, high) covering the air concentration values typically found in Italy (Bernardoni et al. 2011; Bigi et al. 2012; Khana et al. 2016; Lonati et al. 2007; Piazzalunga et al. 2012; Pietrogrande et al. 2016) (Supplementary Information, Table S2). Based on the levoglucosan concentration, different levels of the other sugars were computed as a relative ratio: 0.12 for mannosan and 0.06 for arabitol, mannitol, galactosan, and glucose. These standard solutions were distributed to the participating laboratories, with the exception of laboratories using GC- based techniques.

Three synthetic PM filters were prepared by squirting aqueous standard solutions of the six sugars at 3 different levels onto the quartz filters (samples check L, check M and check H, respectively). An ultrasonic nebulizer (Spectrosonic, Spectro) was used following a procedure described in detail in the Experimental Section of the Supplementary Information (Preparation of synthetic PM filters). A total of twenty-six ambient $\mathrm{PM}_{2.5}$ samples collected in two different locations in Northern Italy Milan (sixteen filters) and Borgo Valsugana, Trento (ten filters) - were analyzed to represent different levels of the target sugars as well as different chemical composition of other contaminants. Milan, the biggest city of Northern Italy, is characterized by high PM levels emitted by different anthropogenic sources (Bernardoni et al. 2011; Bigi et al. 2012; Lonati et al. 2007). The $\mathrm{PM}_{2.5}$ filters were sampled at an urban background station using a high volume automatic outdoor sampler to collect air volumes of $\approx 717 \mathrm{~m}^{3}$ per day on quartz microfiber filters. Each filter had an exposed surface area of $154 \mathrm{~cm}^{2}$ from which $1.5 \mathrm{~cm}^{2}$ punches were taken and sent to the participating laboratories (PM samples MI 1-16).

Borgo Valsugana is a small town of about 7000 inhabitants situated in the Alps, at an altitude of $400 \mathrm{~m}$ in a narrow part of a valley where atmospheric pollutants stagnate during wintertime and where the use of wood burning for domestic heating is extremely diffused (Herich et al. 2014; Khana et al. 2016). A low volume sequential outdoor sampler was used to collect air volumes of $\approx 55 \mathrm{~m}^{3}$ per day on $47 \mathrm{~mm}$ diameter quartz fiber filters. Ten $\mathrm{PM}_{2.5}$ samples sent to the participating 
186 laboratories were prepared by combining 3 punches (each of $0.5 \mathrm{~cm}^{2}$ surface) taken from 3 different 187 filters (samples TN 1-10).

188 A levoglucosan concentration ranging from $\sim 60 \mathrm{ng} \mathrm{m}^{-3}$ to $\sim 1500 \mathrm{ng} \mathrm{m}^{-3}$ was expected in ambient $\mathrm{PM}_{2.5}$ samples, based on literature data (Bernardoni et al. 2011; Bigi et al. 2012; Herich et al. 2014; Khana et al. 2016; Lonati et al. 2007; Pietrogrande et al. 2015).

191 The procedure of sample collection is described in detail in the Experimental Section of the 192 Supplementary Information (Collection and preparation of ambient PM filters).

The samples sent to each participating laboratory were wrapped in aluminum foils and then placed in a zip-lock polyethylene bag. Each receiving laboratory was requested to store the samples in a freezer at $-18^{\circ} \mathrm{C}$ until analysis. The dead-line for reporting the results was set to be within 90 days after shipment.

197

Data Analysis and statistical evaluation of the results. The whole dataset of the participating laboratories was pretreated by eliminating outlying data points (detected by using the Chauvenet's criterion) (Tailor 1997) and properly handling values below detection limit (substituted with a value of half of the detection limit). The median, mean and standard deviation (SD) were calculated for each of the analyzed samples, i.e., 26 real-word $\mathrm{PM}_{2.5}$ samples, 3 synthetic filters and 3 aqueous standard solutions. The interlaboratory precision was estimated by computing the relative standard deviation (RSD\%) for each analyzed sample and the accuracy of each measured result was evaluated by the percentage error $(\varepsilon \%)$ related to median values.

In addition, for each sugar, the outcomes of the intercomparison were investigated as laboratory aggregated results: the concentrations of 29 filters (i.e., 26 ambient and 3 synthetic filters) measured in each laboratory were grouped and the mean and $95 \%$-confidence limits of the data were calculated.

All the details on data analysis are reported in the Experimental Section of the Supplementary Information (Data Analysis).

One-way ANOVA (ANalysis Of VAriance) was applied to single out statistically significant differences among the mean of various laboratories, by choosing a confidence level of $95 \%$. N-way ANOVA was used to determine which factors or combinations of factors are associated with the differences. The investigated factors were the separation techniques (i.e., EC, GC, LC) and the detection systems (i.e., PAD, MS, ${ }^{1} \mathrm{H}-\mathrm{NMR}$ ) used in each analytical method (Table 1) and the sample type for each analyzed sample, i.e., MI, TN, check, solution. 
218 The Principal Component Analysis (PCA) was applied to the dataset as an exploratory tool for 219 singling out the relationships among the objects (analyzed samples) and the variables (laboratories) 220 (Massart et al. 1997).

221 All the details on data analysis are reported in the Experimental Section of the Supplementary 222 Information (Statistical evaluation of the results).

223 All mathematical and statistical computations were performed using the MATLAB 7.5.0 software 224 program.

\section{RESULTS AND DISCUSSION}

Among the 10 participating laboratories, all reported levels for levoglucosan, whereas seven returned concentrations of mannosan and galactosan and only five of the participating laboratories analyzed arabitol, glucose and mannitol. For this reason, the results have been separately evaluated for levoglucosan and the two groups of sugars (i.e., anhydrosugars and biosugars).

Interlaboratory precision: results for levoglucosan. The levoglucosan concentrations measured for each ambient and synthetic filters by each lab are shown in Figure 1, where the mean and standard deviation vales for each sample are reported. From these data, the interlaboratory precision was evaluated by computing the mean concentrations along with the relative standard deviation (RSD) among the labs' results for each sample. These data are summarized in Table 2 and reported in detail in the Supplementary Information Tables S3 and S4. The calculated mean concentration of levoglucosan ranged from $0.05 \mu \mathrm{g}$ punch $^{-1}$ (filter samples MI 2, Table S4) to $13.60 \mu \mathrm{g}$ punch $^{-1}$ (filter sample $\mathrm{TN} 1$ ). This range corresponds to an ambient concentration of levoglucosan ranging from 7 to $2000 \mathrm{ng} \mathrm{m}^{-3}$, under the sampling procedures used in this study. These values represent the range previously observed in cold seasons in the investigated area, with extremely high values at TN (Trento, Borgo Valsugana site), that are consistent with the strong contribution of wood burning for domestic heating in a location close to the Alpine region (Bigi et al. 2012; Herich et al. 2014; Khana et al. 2016).

Overall, the mean RSD of the laboratories for each sample was 41\% (Supplementary Information Table S3) showing an acceptable interlab variability, in comparison with the intralab precision reported by individual methods, showing that most methods had RSD values of $\leq 10 \%$ (Supplementary Information Table S1). A close inspection of RSD as function of solute concentration shows that interlaboratory precision increased with levoglucosan concentration, with a RSD close to $30 \%$ for the samples with concentrations higher than $3 \mu \mathrm{g} \mathrm{punch}^{-1}$ (Table S4). 
Larger interlab variability was found for the Milan samples (mean RSD $45 \%$, Table S3) in comparison with those from Trento with similar levoglucosan concentration (mean RSD $\sim 35 \%$, Table S3). Such additional may be ascribed to the lack of homogeneity in analyte concentration on the large surface $\left(154 \mathrm{~cm}^{2}\right)$ filters used for collecting PM samples in Milan. A homogeneity test was performed on such filters in the lab EC-PAD2 by submitting to levoglucosan analysis 15 punches taken from the same filter (test repeated on 3 different filters). A mean relative standard deviation of $7 \% \pm 3 \%$ was obtained, that gives an indication that most of the variation increase in the Milan data could be attributed to the inherent variability in the large filters, in agreement with what was before reported by Yttri et al. (2015).

In order to investigate the contribution of the intrinsic variations of the different methods, the intercomparison study was performed also on three aqueous standard solutions containing known amounts of levoglucosan. Only eight of the participating laboratories delivered such data, since the two GC-based methods are excluded as the sample preparation methodology requires solvents instead of water for the extraction procedure (Table 1). In general, the obtained results show good interlaboratory precision (RSD\% 17\%) independent of analyte concentration (Supplementary Information Table S3 and Table S4).

The contribution of each laboratory to the total variability was investigated in detail by reporting the outcomes of the study as laboratory aggregated results by grouping the concentrations of the 29 filters measured in each laboratory (Table 2). One-way ANOVA analysis was applied to the data in order to single out significant differences in the mean values of each laboratory (ANOVA Tables are reported in the Supplementary Information Table S6 only for the statistically significant models at confidence level of $95 \%$ ). A multiple comparison procedure was then applied to identify the laboratories that produced such significantly different results $(p<0.05)$. The labs EC-PAD4, ECPAD5 and GC-MS2 were found to deliver significantly lower results and the lab NMR higher data (values in bold in Table 2).

Then N-way ANOVA was applied to separately single out the different factors that contribute to the variability of the final results, namely the sample type and the procedure characteristics, as reported in Table 1. The data of the NMR lab were excluded from such a computation for the lack of result generalization, since only one lab using ${ }^{1} \mathrm{H}-\mathrm{NMR}$ detection without preliminary separation was included in this study. Two separated two-way models were investigated using pairs of factors (separation-sampling site and detection-sampling site), since the three-way models based on all factors show missing factor combinations. The ANOVA Tables of the two models show that the sampling site is the only parameter having a significant effect $(\mathrm{p} \sim 0)$ on the measurement variability, while differences in separation techniques - IC, LC and GC - as well as in detection 
systems - PAD and MS - don't significantly $(\mathrm{p}<0.05)$ affect the mean values measured in the nine investigated laboratories.

Interlaboratory precision: results for anhydrosugars. Mannosan and galactosan were analyzed in 7 of the ten participating laboratories, excluding labs EC-PAD4, EC-PAD5 and NMR (concentration values reported in Figures 2 and 3, mean and relative standard deviation summarized in Table 2 and reported in detail in the Supplementary Information Tables S3 and S5).

The calculated mean concentration ranged from 0.02 to $2.0 \mu \mathrm{g} \mathrm{punch}^{-1}$ for mannosan $-3-300 \mathrm{ng}$ $\mathrm{m}^{-3}$ in ambient air - and from 5 to $800 \mathrm{ng} \mathrm{punch}^{-1}-0.7-130 \mathrm{ng} \mathrm{m}^{-3}-$ for galactosan (Table S5). These values are consistent with those observed in Italian urban and rural areas, in particular during wintertime characterized by a strong impact of wood burning (Bernardoni et al. 2011; Bigi et al. 2012; Khana et al. 2016; Lonati et al. 2007; Piazzalunga et al. 2012; Pietrogrande et al. 2016).

Similar interlaboratory precision was found for the 2 anhydrosugars (total mean RSD $\%=38 \%$ ), that is close to the mean $\mathrm{RSD} \%=34 \%$ obtained for levoglucosan in the same laboratories.

When the data are grouped according to sample types, a pattern similar to that of levoglucosan is observed, with larger variability for PM filters collected in Milan described by a mean RSD\% value of $40 \%$ and $46 \%$ for mannosan and galactosan, respectively (Supplementary Information Table S3). Five of the participating laboratories analyzed the aqueous standard solutions of mannosan and galactosan, i.e., EC-PAD1, EC-PAD2, EC-PAD3, EC-MS and LC-MS (detailed results in Supplementary Information Tables S3 and S5). The data show an excellent precision for galactosan (i.e., $\mathrm{RSD} \%=12 \%)$, and still better for mannosan $(\mathrm{RSD} \%=6 \%)$.

The concentration data of the 29 filters measured in each laboratory were aggregated by laboratory in order to single out the contribution of each laboratory to the total variability (Table 2). The good comparability among the procedures is supported by similar mean values among the laboratories with no statistically significant difference $(\mathrm{p}<0.05)$ singled out by one-way ANOVA analysis.

Interlaboratory precision: results for biosugars. The study was extended to the most common saccharides present in vascular plants and microorganisms (i.e. arabitol, glucose and mannitol). Glucose has been proposed as source-specific tracers for soil biota released into the atmosphere by farmland soil suspension and natural soil erosion (Jia et al. 2010; Kourtchev et al. 2011; Medeiros et al. 2006; Pietrogrande et al. 2015, 2016). In addition, monosaccharides, mainly glucose, can be emitted as uncombusted material during the burning process of wood, where they are present as hemicellulose constituents (Medeiros et al. 2006). Sugar alcohols, as arabitol and mannitol, have been used as biomarkers to estimate atmospheric fungal spore abundance (Jia et al. 2010; Kourtchev et al. 2011; Medeiros et al. 2006). 
Biosugars were measured in five of the participating laboratories, i.e., labs EC-PAD1, EC-PAD2, GC-MS2, EC-MS and LC-MS - all mannitol data below the detection limit - (mean concentration and relative standard deviation reported in Tables 2 and Table S3, Supplementary Information). In the investigated samples, similar concentrations were found for arabitol and mannitol, with values ranging from 8 to $200 \mathrm{ng}$ punch $^{-1}$ (ambient concentration: 1 to $30 \mathrm{ng} \mathrm{m}^{-3}$ ). Nearly double concentrations were measured for glucose in the 20-400 ng punch ${ }^{-1}$ range $\left(3-60 \mathrm{ng} \mathrm{m}^{-3}\right)$. These values are consistent with those observed in Italian urban and rural areas: higher values at the Milan site can be explained by the concomitant contribution of several emission sources (Bernardoni et al. 2011; Bigi et al. 2012; Lonati et al. 2007; Pietrogrande et al. 2015).

The evaluation of the interlaboratory precision showed good reproducibility for arabitol (RSD\% $26 \%$ ) and still acceptable for glucose and mannitol (RSD $\% \sim 40 \%$, with the exception of the samples collected at Trento, $\mathrm{RDS} \%=62 \%$, Supplementary Information Table S3). It must be underlined that the concentration range investigated for biosugars (0.02-0.2 $\left.\mu \mathrm{g} \mathrm{punch}^{-1}\right)$ was more limited in comparison with that studied for anhydrosugars (from 0.02 to $2 \mu \mathrm{g} \mathrm{punch}^{-1}$ and even to 12 $\mu \mathrm{g}$ punch $^{-1}$ for levoglucosan), as typical levels commonly found in real world samples.

The one-way ANOVA analysis on the results aggregated by laboratories showed that there were not statistically significant differences $(\mathrm{p}<0.05)$ among the mean values of the 5 laboratories (Table 2). Concerning the analysis of aqueous standard solutions of biosugars, excellent precision was found for glucose and mannitol (RSD $\% \sim 6 \%$, Table 2) and good for arabitol (RSD $\%=10 \%$ ).

Despite this study is limited to a few participant laboratories and therefore the comparison with the other determined sugars is poor, the obtained results confirm the generally good interlaboratory precision, with none of the participants distinguishing themselves by reporting significantly higher (or lower) results.

Measurement accuracy: results for levoglucosan. Measure accuracy was evaluated by percentage error $(\varepsilon \%)$ calculated for levoglucosan results of each of the twenty nine filters analyzed in the 10 participating laboratories $(\varepsilon \%$ calculation and detailed results in the Supplementary Information Table S4). From these data the mean values were computed for all the samples (total mean, Table 3) as well as from separated groups (i.e., samples collected at Milan, Trento or synthetic samples) (Supplementary Information Table S3, mean MI, mean TN, mean check). The mean $\varepsilon \%$ for the various samples ranged from -11 to +33 that is consistent with the overall accuracy of each analytical method (Supplementary Information Table S1). This result is even better by considering that $\varepsilon \%$ values decrease to a narrower range from $-6 \%$ to $+12 \%$, for the samples with concentration higher than $4 \mu \mathrm{g}$ punch $^{-1}$. The data show a variation with the sample type, with the filters collected 
in Milan affected by higher errors $(\varepsilon \% \sim 8 \%)$ in comparison with those from Trento $(\varepsilon \% \sim-1 \%)$ with similar levoglucosan concentration $\leq 4 \mu \mathrm{g} \operatorname{punch}^{-1}$ (mean MI, mean TN).

The original $\varepsilon \%$ values were aggregated by laboratory and the mean $\varepsilon \%$ was calculated for each of the 10 laboratories to separately investigate the accuracy of each laboratory (Table 3 ). From the data it can be seen that of the ten participating laboratories, six have mean $\varepsilon \%$ values within $\pm 25 \%$ (labs. EC-PAD1, EC-PAD2, EC-PAD5, GC-MS1, GC-MS2 and LC-MS), which should be considered a narrow range. The labs EC-PAD3 and EC-PAD4 delivered less accurate data with $\varepsilon \%$ values close to $30 \%$ and the NMR lab with $\varepsilon \%$ higher than $40 \%$. In general, the accuracy found in this study is better than that (from -63 to 20\%) reported by Yttri et al. (2015) in a similar inter-comparison study involving 13 laboratories using EC-PAD, EC-MS, LC-MS and GC-MS methods.

The ANOVA of the data singles out statistically significant differences $(p<0.05)$ among the mean values of the laboratories (Supplementary Information Table S6). A multiple comparison procedure showed that such differences are due to the most negatively biased results obtained in the labs ECPAD4, EC-PAD5 and GC-MS2 (-26.6\%, $-22.4 \%$ and $-21.9 \%$, respectively) and the most positively biased data from the labs NMR and EC-PAD (47.0\% and 43.8\%, respectively) (values in bold in Table 3).

Then to identify the contribution to the measure uncertainty of the separation, detection and site factors, N-way ANOVA was applied to the data of nine labs, excluding the NMR lab, since it is the only laboratory using an analytical technique without preliminary separation. The ANOVA results show that differences neither in sample type nor in separation techniques and detection systems have a significant effect $(\mathrm{p}<0.05)$ on the result accuracy of the nine participating laboratories.

Measurement accuracy: results for anhydrosugars. The analytical accuracies for mannosan and galactosan were investigated by computing $\varepsilon \%$ for the 29 samples analyzed in 7 laboratories (labs EC-PAD4, EC-PAD5 and NMR don't measure such analytes) (total mean in Table 3, detailed results in the Supplementary Information Table S5). Good accuracies were found, as described by the mean $\varepsilon \%$ values ranging from -22 to $14 \%$ for mannosan (total mean $-3.6 \%$ ) and from $-11 \%$ to $22 \%$ for galactosan (total mean $1.3 \%$ ). The excellent accuracy is confirmed by evaluating the data grouped by sample type, since a good precision is observed even for the less concentrated filters collected in Milan $(\varepsilon \%=-4.7 \%$ and $2.8 \%$ for mannosan and galactosan, respectively, Supplementary Information Table S5).

The accuracy of each laboratory was evaluated by aggregating the original $\varepsilon \%$ values by laboratory (Table 3). Good accuracy was obtained for mannosan, as described by $\varepsilon \%$ ranging from -37 to $23 \%$. Five of the seven participating laboratories, corresponding to $72 \%$ of the laboratories, yielded mean 
$\varepsilon \%$ values within $\pm 18 \%$ range. Indeed, two of them (EC-PAD3 and EC-MS) show an exceptionally narrower range of $\pm 2 \%$. Similar accuracy was found for galactosan ( $\varepsilon \%$ from $-51 \%$ to $28 \%$ ), with $\varepsilon \%$ values within $\pm 10 \%$ for five laboratories, corresponding to $72 \%$ of the laboratories (labs ECPAD1, EC-PAD3, EC-MS, GC-MS1, GC-MS2 and LC-MS, Table 3 ). These percentage errors are substantially narrower than those recently reported by Yttri et al. (2015) that found wider errors ranging from 60 to $69 \%$ for mannosan and still wider from to -84 to $68 \%$ for galactosan.

The ANOVA of the data singles out similar behavior of mannosan and galactosan accuracy with significantly $(\mathrm{p}<0.05)$ less accurate results obtained in lab EC-PAD2 $(-37.2 \%$ and $-50.8 \%$ for mannosan and galactosan, respectively) and lab LC-MS ( $25 \%$ for both sugars), as indicated by the multiple comparison procedure (values in bold in Table 3). For both sugars, the results of N-way ANOVA show that among the investigated factors - separation, detection and site - the separation type displays a significant effect on $\varepsilon \%$, as a single parameter $(\mathrm{p}<0.002$ and $\mathrm{p}<0.01$, for mannosan and galactosan, respectively) and as interaction term (site*sep) $(\mathrm{p}<0.002$ and $\mathrm{p}<0.01$, for mannosan and galactosan, respectively) (Supplementary Information Table S6). This effect is likely due to the large bias of the results obtained with the LC-MS method. However, any general conclusion cannot be drawn from this study, since only one of the participating laboratories used this procedure.

The intrinsic accuracy of the different laboratories was evaluated by computing the percentage error, $\varepsilon \%$, for the aqueous standard solutions (related to the true concentration in each solution, as reported in Supplementary Information Table S1). For levoglucosan, an excellent accuracy (mean $\varepsilon \% \leq 3 \%$ ), independent of standard concentrations, was found for the 8 participating laboratories (Supplementary Information Table S3, mean soln, and Table S4, detailed values). Even better accuracy was obtained for mannosan and galactosan, with mean $\varepsilon \% \leq 1 \%$, independent of standard concentrations (Supplementary Information Table S3, mean soln, and Table S5, detailed values).

Measurement accuracy: results for biosugars. For biosugars, the $\varepsilon \%$ values computed from the data of the participating laboratories show an excellent accuracy ( $\varepsilon \%$ within $\pm 8 \%$ range), as the total mean computed on all the samples (within $\pm 5 \%$ range, total mean, Table 3 ) as well as the grouped values according to sample type ( $\varepsilon \% \leq 7 \%$, Supplementary Information Table S3), indicating that the measurement accuracy is not affected by the analyte concentration and matrix complexity, within the concentration range investigated $\left(0.02-0.7 \mu \mathrm{g}\right.$ punch $\left.^{-1}\right)$. Within the limits of the low number of participating laboratories, this is a very comforting result, considering the low concentration levels of the measured biosugars. 
By aggregating the original $\varepsilon \%$ values by laboratory and calculating the mean $\varepsilon \%$ was for each sugar, we can observe a general good accuracy for arabitol and mannitol in all the laboratories, as described by the obtained $\varepsilon \%$ mostly within $\pm 10 \%$ range. (Table 3 ). Less accurate data were obtained for glucose, since the mean $\varepsilon \%$ values ranged from $-40 \%$ to $+20 \%$ (Table 3 ).

The mean values of the laboratories show statistically significant differences $(p<0.05)$ that were singled out by ANOVA analysis (Supplementary Information Table S6). The multiple comparison procedure showed that for arabitol significantly more negatively biased data are obtained from the lab EC-PAD1 $(\varepsilon \% \sim-20 \%)$ in comparison with the other laboratories (value in bold in Table 3). For glucose, less accurate results were obtained from the labs EC-PAD2 and LC-MS that largely underestimated the results $(\varepsilon \%=-40 \%$ and $-30 \%$, respectively) and, regarding mannitol, significantly more overestimated values were provided by the GC-based method $(\varepsilon \%=51 \%$ for GC-MS2 lab) (values in bold in Table 3).

For the aqueous standard solutions, the mean percentage error, $\varepsilon \%$ values shows variable results with low $\varepsilon \% \leq 2 \%$ for glucose and mannitol, but as high as $-10.9 \%$ for arabitol (Supplementary Information Table S3). It must be underlined that these results may be invalided by the limited number of the laboratories that delivered the results, i.e., 4 for arabitol and glucose and 3 for mannitol.

Principal Component Analysis of laboratory accuracy. Finally, the PCA analysis was performed on the accuracy data of the five laboratories that analyzed all the six sugars, i.e., EC-PAD1, ECPAD2, EC-MS, LC-MS and GC-MS2. The model was applied to 18 objects describing the mean percentage error, $\varepsilon \%$, computed from all the filters and separately from the Milan and Trento samples. In the computed PCA model, the sum of PC1, PC2 and PC3 explained $87 \%$ of the total variance of the data: $\mathrm{PC} 1=38 \%, \mathrm{PC} 2=28 \%$ and $\mathrm{PC} 3=21 \%$. The simultaneously depiction of the loadings and scores as a biplot makes it possible to simply visualize the effect of the different methods on measurement accuracy (Figure 4). The plot shows that the PC1 axis clearly discriminates two groups of liquid-based procedures, namely EC-PAD2 and EC-MS laboratories, with positive loadings located on the right side of the plot, and EC-PAD1 and LC-MS laboratories, with negative PC1 values. The PC2 axis distinguishes the separation methods, with positive loadings only for the gas-based method GC-MS2. The proximity among sugar scores and method loadings depicts how each method over/under estimates the sugar results. Levoglucosan is mostly overestimated by the EC-MS method ( $\varepsilon \%=47 \%$, Table 3 ) and underestimated by the EC-PAD1 and GC-MS2 labs ( $\varepsilon \%=-7.2 \%$ to $-21.9 \%$, respectively). Mannosan and galactosan scores show a similar pattern, being overestimated by EC-PAD1 and LC-MS laboratories, mainly the LC-MS lab $(\varepsilon \% \sim 25 \%)$, and underestimated by the EC-PAD2 lab $(\varepsilon \%=-37.2 \%$ and $-50.8 \%$ for mannosan and 
galactosan, respectively). EC-PAD2 laboratory produces positively biased values of arabitol $(\varepsilon \%=$ $8.8 \%)$ and EC-PAD1 negatively biased results $(\varepsilon \%=-19.6 \%)$. Glucose and mannitol scores show a similar pattern, with overestimated values delivered by the GC-MS2 laboratory, mainly for mannitol $(\varepsilon \%=50.9 \%)$. In addition, for glucose the EC-PAD2 and LC-MS labs produce negatively biased results $(\varepsilon \%=-40.3 \%$ and $-30 \%$ for EC-PAD2 and LC-MS, respectively, Table 3$)$. These results confirm that among the various laboratories the differences in measurement accuracy, although in general not statistically significant, cannot be attributed to a specific subclass of analytical methods for the six sugars.

\section{CONCLUSIONS}

In the current study we compared the results of 10 laboratories that analyzed sugars in ambient aerosol samples using the most common methods reported in the scientific literature so far.

More general conclusions may be drawn for levoglucosan (based on data of ten participating laboratories) and somewhat less for mannosan and galactosan (seven laboratories), while only limited information for biosugars (five and four laboratories).

As a general conclusion, the results obtained are encouraging with respect to precision and accuracy and suggest that levels of the investigated sugars in PM samples obtained by most common analytical methods provide comparable results. This is proved by good interlaboratory precision of the various analytical methods, as defined by RSD ranging from 25 to $46 \%$, and acceptable accuracy varying from -2 to $51 \%$, and within $\pm 20 \%$ for 8 of the 10 participating laboratories.

Despite the fact that the investigated methods - in terms of extraction procedure and derivatization agent, chromatographic separation and detection systems - prevents us from comparing the performance of different subclasses of analytical methods, some general conclusions emerge from the data.

First, the procedures involving liquid (EC and LC) and gas chromatography provide similar results, despite the GC-based procedures are by far the most commonly used one within the research community and they also have the longest record of use. Consequently, the present results show that the more recently developed LC and EC methods are suitable to provide reliable results, despite the shorter experience associated with these less widespread analytical procedures.

Second, the different extraction conditions, i.e., water versus solvent, involving silyl derivatization, have a negligible influence on the obtained results at the concentration levels investigated in this study.

Finally, no significant differences can be attributed to the choice of the detection system, such as PAD or mass spectrometry. 
However, because of a certain degree of variability between laboratories, results from this study clearly demonstrate that attention must be payed to quality assurance of each laboratory procedure in terms of intralaboratory precision and accuracy that are particularly challenging for highly complex samples such as PM collected in urban sites.

\section{REFERENCES}

Barbaro, E., Kirchgeorg, T., Zangrando, R., Vecchiato, M., Piazza, R., Barbante, C., Gambaro, A., 2015. Sugars in antartic aerosol. Atmospheric Environment 118, 135-144.

Bernardoni, V., Vecchi, R., Valli, G., Piazzalunga, A., Fermo, P., 2011. PM10 source apportionment in Milan (Italy) using time-resolved data. Science of the Total Environment 409, 4788-4795.

Bigi, A., Ghermandi, G., Harrison, R.M., 2012. Analysis of the air pollution climate at a background site in the Po valley. Journal of. Environmental Monitoring 14, 552-563.

Calvo, A.I., Alves, C., Castro, A., Pont, V., Vicente A.M., Fraile, R., 2013. Research on aerosol sources and chemical composition: Past, current and emerging issues. Atmospheric Research 120$121,1-28$.

Calvo, A.I., Martins, V., Nunes, T., Duarte, M., Hillamo, R., Teinilae, K ., Pont, V., Castro, A., Fraile, R., Tarelho, L, Alves, C., 2016. Residential wood combustion in two domestic devices: Relationship of different parameters throughout the combustion cycle. Atmospheric Research 116, 72-82.

Caseiro, A., Marr, I.L., Claeys, M., Kasper-Giebl, A., Puxbaum, H., Pio, C.A., 2007. Determination of saccharides in atmospheric aerosol using anion-exchange high-performance liquid chromatography and pulsed-amperometric detection. Journal of Chromatography A 1171, 37-45.

Decesari, S., Fuzzi, S., Facchini, M.C., Mircea, M., Emblico, L., Cavalli, F., Maenhaut, W., Chi, X., Schkolnik, G., Falkovich, A., Rudich, Y., Claeys, M., Pashynska, V., Vas, G., Kourtchev, I., Vermeylen, R., Hoffer, A., Andreae, M.O., Tagliavini, E., Moretti, F., Artaxo, P., 2006. Characterization of the organic composition of aerosols from Rondônia, Brazil, during the LBASMOCC 2002 experiment and its representation through model compounds. Atmospheric Chemistry and Physics 6, 375-402.

Fabbri, D., Modelli, S., Torri, C., Cemin, A., Ragazzi, M., Scaramuzza, P., 2008. GC-MS determination of levoglucosan in atmospheric particulate matter collected over different filter materials. Journal of Environmental Monitoring 10, 1519-1523.

Herich, H., Gianini, M.F.D., Piot, C., Mocnik, G., Jaffrezo J.L., Besombes, J.L., Prévôt, A.S.H., Hueglin, C., 2014. Overview of the impact of wood burning emissions on carbonaceous aerosols and PM in large parts of the Alpine region. Atmospheric Environment 89, 64-75.

Hsu, C.L., Cheng, C.Y., Lee, C.T., Ding, W.H., 2007. Derivatization procedures and determination of levoglucosan and related monosaccharide anhydrides in atmospheric aerosols by gas chromatography-mass spectrometry. Talanta 72, 199-205. 
Jia, Y., Bhat, S., Fraser, M.P., 2010. Characterization of saccharides and other organic compounds in fine particles and the use of saccharides to track primary biologically derived carbon sources. Atmospheric Environment 44, 725-732.

Khana, M.B., Masiol, M., Formenton, G., Di Gilio, A., de Gennaro, G., Agostinelli, C., Pavoni, B., 2016. Carbonaceous PM2.5 and secondary organic aerosol across the Veneto region (NE Italy). Science of the Total Environment 542, 172-181.

Kourtchev, I., Hellebust, S., Bell, J.M., O'Connor, I.P., Healy, R.M., Allanic, A., Healy, D., Wenger, J.C., Sodeau, J.R., 2011. The use of polar organic compounds to estimate the contribution of domestic solid fuel combustion and biogenic sources to ambient levels of organic carbon and PM2.5 in Cork Harbor, Ireland. Science of the Total Environment 409, 2143-2155.

Lonati, G., Ozgen, S., Giugliano, M., 2007. Primary and secondary carbonaceous species in PM2.5 samples in Milan (Italy). Atmospheric Environment 41, 4599-4610

Lundstedt, S., Bandowe, B.A.M., Wilcke, W., Boll, E., Christensen, J.H., Vila, J., Grifoll, M., Faure, P., Biache, C., Lorgeoux, C., Larsson, M., Frech Irgum, K., Ivarsson, P., Ricci, M., 2014. First intercomparison study on the analysis of oxygenated polycyclic aromatic hydrocarbons (oxyPAHs) and nitrogen heterocyclic polycyclic aromatic compounds (N-PACs) in contaminated soil. TrAC-Trend in Analytical Chemistry 57, 83-92.

Massart, D.L., Vandeginste, B.G.M., Buydens, L.M.G., De Song, S., Lewi, P.J., Smeyers-Verbeke, J., 1997. Handbook of Chemometrics and Qualimetrics (Part A), Elsevier Science, Amsterdam.

Medeiros, P.M., Conte, M.H., Weber, J.C., Simoneit, B.R.T., 2006. Sugars as source indicators of biogenic organic carbon in aerosols collected above the Howland Experimental Forest, Maine. Atmospheric Environment 40, 1694-1705.

Paglione, M., Saarikoski, S., Carbone, S., Hillamo, R., Facchini, M.C., Finessi, E., Giulianelli, L., Carbone, C., Fuzzi, S., Moretti, F., Tagliavini, E., Swietlicki, E., Stenstrom, K.E., Prevot, A.S. H., Massoli, P., Canaragatna, M., Worsnop, D., Decesari, S., 2014. Primary and secondary biomass burning aerosols determined by proton nuclear magnetic resonance (H-1-NMR) spectroscopy during the 2008 EUCAARI campaign in the Po Valley (Italy). Atmospheric Chemistry and Physics $14,5089-5110$.

Pashynska, V., Vermeylen, R., Vas, G., Maenhaut, W., Claeys, M., 2002. Development of a gas chromatographic/ion trap mass spectrometric method for the determination of levoglucosan and saccharidic compounds in atmospheric aerosols. Application to urban aerosols. Journal of Mass Spectrometry 37, 1249-1257.

Perrone, M. G., Gualtieri, M., Consonni, V., Ferrero, L., Sangiorgi, G., Longhin, E., Ballabio, D., Bolzacchini, E., Camatini, M., 2013. Particle size, chemical composition, seasons of the year and urban, rural or remote site origins as determinants of biological effects of particulate matter on pulmonary cells. Environmental Pollution 176, 215-227.

Piazzalunga, A., Fermo, P., Bernardoni, V., Vecchi, R., Valli, G., De Gregorio, M. A. 2012. A simplified method for levoglucosan quantification in wintertime atmospheric particulate matter by high-performance anion-exchange chromatography coupled with pulsed amperometric detection. International Journal of Environmental Analytical Chemistry 90, 934-947. 
Pietrogrande, M.C., Bacco, D., Chiereghin, S., 2013. GC/MS analysis of water-soluble organics in atmospheric aerosol: optimization of a solvent extraction procedure for simultaneous analyis of carboxylic acids and sugars. Analytical and Bioanalytical Chemistry 405, 1095-1104.

Pietrogrande, M.C., Bacco, D., Ferrari, S., Kaipainen, J., Ricciardelli, I., Riekkola, M.-L., Trentini, A., Visentin, M., 2015. Polar organic marker compounds in atmospheric aerosol in the Po valley during the Supersito campaigns- Part 3: Contribution of wood combustion to wintertime atmospheric aerosols in Emilia Romagna region (Northern Italy). Atmospheric Environment 122, 291-305.

Pietrogrande, M.C., Bacco, D., Ferrari, S., Ricciardelli, I., Scotto, F., Trentini A., Visentin, M., 2016. Characteristics and major sources of carbonaceous aerosols in PM2.5 in Emilia Romagna Region (Northern Italy) from four-year observations. Science of the Total Environment 553, 172183.

Piot, C., Jaffrezo, J.L., Cozic, J., Pissot, N., El Haddad, I., Marchand, N., Besombes, J.L., 2012. Quantification of levoglucosan and its isomers by High Performance Liquid ChromatographyElectrospray Ionization tandem Mass Spectrometry and its applications to atmospheric and soil samples Atmospheric Measurement Techniques 5, 141-148.

Puxbaum, H., Caseiro, A., Sanchez-Ochoa, A., Kasper-Giebl, A., Claeys, M., Gelencsér, A., Legrand, M., Preunkert, S., Pio, C., 2007. Levoglucosan levels at background sites in Europe for assessing the impact of biomass combustion on the European aerosol background. Journal of Geophysical Research: Atmosphere 112, doi:10.1029/2006JD008114.

Schkolnik, G., Rudich, Y., 2006. Detection and quantification of levoglucosan in atmospheric aerosols: A review. Analytical and Bioanalytical Chemistry 385, 26-33.

Tailor, J.R., 1997. Introduction to Error Analysis, the Study of Uncertainties in Physical Measurements, 2nd ed, University Science Books, New York.

Vanderford, B.I., Jörg, E.D., Eaton, A., Yingbo C.G, Haghani, A., Hoppe-Jones, C., Schluesener, M.P., Snyder, S.A., Ternes, T., Wood, C.J., 2014. Results of an inter laboratory comparison of analytical methods for contaminants of emerging concern in water. Analytical Chemistry 86, 774782.

Xu, Z., Wen, T., Li , X., Wang, J., Wang, Y., 2015. Characteristics of carbonaceous aerosols in Beijing based on two-year observation. Atmospheric Pollution Research 6, 202-208.

Yttri, K.E., Schnelle-Kreis, J., Maenhaut, W., Abbaszade, G., Alves, C., Bjerke, A., Bonnier, N., Bossi, R., Claeys, M., Dye, C., Evtyugina, M., Garcia-Gacio, D., Hillamo, R., Hoffer, A., Hyder, M., Iinuma, Y., Jaffrezo, J.-L., Kasper-Giebl, A., Kiss, G., Lopez-Mahia, P.L., Pio, C., RamirezSanta-Cruz, C., Sciare, J., Teinila, K., Vermeylen, R., Vicente, A., Zimmermann, R., 2015. An intercomparison study of analytical methods used for quantification of levoglucosan in ambient aerosol filter samples. Atmospheric Measurement Techniques 8, 125-147. 


\section{Tables, Figures and Caption}

Table 1. Overview and short description of the analytical methods used by the participating laboratories in the present intercomparison: instrument used for separation and detection of the analytes, chromatographic column used for separation, solvent(s) used for extraction (solvent volume and ultrasonication duration) and whether derivatization of the analytes was applied.

\begin{tabular}{|c|c|c|c|}
\hline $\begin{array}{l}\text { Laboratory } \\
\text { code }\end{array}$ & Analysis Instrument & Separation Column & $\begin{array}{l}\text { Extraction solvent/ } \\
\text { derivatization }\end{array}$ \\
\hline EC-PAD1 & Dionex ICS2500 & Metrosep Carb-2- CO3 Trap-1/ & water (15 ml, 60’) \\
\hline EC-PAD2 & Metrohm 886- Metrohm & Metrosep Carb-2 CO3 Trap-1/ & water (15 ml, 30') \\
\hline EC-PAD $3^{16}$ & Dionex ICS1000 & Dionex CarboPac PA20 column & water (15 ml, 60') \\
\hline EC-PAD $4^{16}$ & Dionex - ECD-3000RS & Dionex CarboPac PA10 column & water (15 ml, 60’) \\
\hline EC-PAD5 ${ }^{16}$ & DC3000 & Dionex CarboPac PA10 column & water (15 ml, 30’) \\
\hline $\mathrm{EC}-\mathrm{MS}^{19}$ & $\begin{array}{c}\text { Dionex ICS } 5000 \text { - ESI(-) single } \\
\text { quadrupole MSQ }\end{array}$ & $\begin{array}{c}\text { DionexCarboPac } \\
\text { PA10column (glucose) } \\
\text { MA1 column (others) }\end{array}$ & water (7 ml, 14' x 2) \\
\hline GC-MS1 $1^{13}$ & GC-MS (quadrupole) (Agilent) & DB-5MS column & $\begin{array}{l}\text { Acetonitrile }\left(15 \mathrm{ml} 20^{\prime} \times 2\right) / \\
\text { BSTFA derivatization }\end{array}$ \\
\hline GC-MS2 $2^{15}$ & GC - MS (ion trap) (Thermo) & DB-5MS column & $\begin{array}{c}\text { Methanol:dichloromethane }\left(9: 1,15 \mathrm{ml}, 30^{\prime}\right) / \\
\text { BSTFA derivatization }\end{array}$ \\
\hline LC-MS & $\begin{array}{l}\text { UHPLC (Ultimate 3000RS) } \\
\text { HQOMS (Q-Orbitrap) }\end{array}$ & $\begin{array}{l}\text { RCM-Monosaccharide } \mathrm{Ca}^{+2} \\
(8 \%) \text { column }\end{array}$ & water (15 ml, 30') \\
\hline $\mathrm{NMR}^{20}$ & Varian Unity INOVA $600 \mathrm{MHz}$ & & water (15 ml, 60’) \\
\hline
\end{tabular}




\begin{tabular}{|c|c|c|c|c|c|c|c|c|c|c|c|}
\hline $\begin{array}{l}\text { concentration } \\
\left(\mu \mathrm{g} \text { punch }^{-1}\right)\end{array}$ & Total & $\begin{array}{l}\text { EC- } \\
\text { PAD1 }\end{array}$ & $\begin{array}{c}\text { EC- } \\
\text { PAD2 }\end{array}$ & $\begin{array}{l}\text { EC- } \\
\text { PAD3 }\end{array}$ & $\begin{array}{l}\text { EC- } \\
\text { PAD4 }\end{array}$ & $\begin{array}{l}\text { EC- } \\
\text { PAD5 }\end{array}$ & EC-MS & GC-MS1 & GC-MS2 & LC-MS & NMR \\
\hline \multicolumn{12}{|l|}{ Levoglucosan } \\
\hline mean & 3.61 & 3.69 & 3.17 & 4.06 & 1.84 & 2.82 & 3.52 & 4.00 & 2.81 & 4.27 & 6.72 \\
\hline I.C. & 1.43 & 1.64 & 1.43 & 1.80 & 1.05 & 1.23 & 1.87 & 1.47 & 1.28 & 1.88 & 1.60 \\
\hline \multicolumn{12}{|l|}{ Mannosan } \\
\hline mean & 0.48 & 0.50 & 0.52 & 0.72 & & & 0.49 & 0.38 & 0.40 & 0.50 & \\
\hline I.C. & 0.29 & 0.22 & 0.31 & 0.34 & & & 0.25 & 0.15 & 0.20 & 0.22 & \\
\hline \multicolumn{12}{|l|}{ Galactosan } \\
\hline mean & 0.20 & 0.20 & 0.12 & 0.22 & & & 0.29 & 0.16 & 0.24 & 0.33 & \\
\hline I.C. & 0.12 & 0.09 & 0.08 & 0.11 & & & 0.13 & 0.06 & 0.10 & 0.12 & \\
\hline \multicolumn{12}{|l|}{ Arabitol } \\
\hline mean & 0.12 & 0.12 & 0.11 & & & & 0.06 & & 0.13 & 0.22 & \\
\hline I.C. & 0.12 & 0.12 & 0.08 & & & & 0.04 & & 0.10 & 0.18 & \\
\hline \multicolumn{12}{|l|}{ Glucose } \\
\hline mean & 0.25 & 0.28 & 0.14 & & & & 0.24 & & 0.27 & 0.15 & \\
\hline I.C. & 0.11 & 0.13 & 0.14 & & & & 0.11 & & 0.11 & 0.10 & \\
\hline \multicolumn{12}{|l|}{ Mannitol } \\
\hline mean & 0.15 & 0.17 & 0.13 & & & & 0.10 & & 0.47 & & \\
\hline I.C. & 0.14 & 0.15 & 0.12 & & & & 0.07 & & 0.30 & & \\
\hline
\end{tabular}

Table 2. Results of interlaboratory precision study: concentrations of six sugars analyzed in 29 filters -26 ambient $\mathrm{PM}_{2.5}$ and 3 synthetic filters - expressed as $\mu \mathrm{g}$ punch ${ }^{-1}$, with $1.5 \mathrm{~cm}^{2}$ punch surface area: mean values (mean) and confidence limit (I.C. at $\mathrm{p}<$ 0.05). Total values were computed from all the data measured in ten laboratories for levoglucosan, seven for mannosan and galactosan, five for arabitol and glucose, four for mannitol.

Aggregated laboratory values were computed from the samples analyzed in each laboratory. Values in bold are laboratory means significantly $(\mathrm{p}<0.05)$ different from the others. 
Table 3. Results of measurement accuracy for six sugars evaluated as mean percentage error $(\varepsilon \%)$ computed in 29 analyzed filters 26 ambient $\mathrm{PM}_{2.5}$ and 3 synthetic filters - : mean values (mean) and confidence limit (I.C. at $\mathrm{p}<0.05$ ). Total values were computed from all the data measured in ten laboratories for levoglucosan, seven for mannosan and galactosan, five for arabitol and glucose, four for mannitol.

Aggregated laboratory values were computed from the samples analyzed in each laboratory. Values in bold are laboratory means significantly $(\mathrm{p}<0.05)$ different from the others.

\begin{tabular}{ccccccccccc}
\hline$\varepsilon \%$ & Total & EC- & EC- & EC- & EC- & EC- & EC- & & & \\
& PAD1 & PAD2 & PAD3 & PAD4 & PAD5 & MS & GC-MS1 & GC-MS2 & LC-MS & NMR
\end{tabular}

\section{Levoglucosan}

mean

$4.4-7.2-6.2$

I.C.

$\begin{array}{lll}4.1 & 7.3 & 11.6\end{array}$

$-26.6$

$-22.4 \quad 47.0$

19.1

$-21.9$

43.8

16.0

18.0

4.8

12.8

14.9

5.7

Mannosan

mean

$\begin{array}{llll}-3.6 & 10.5 & \mathbf{- 3 7 . 2} & 2.4 \\ 2.7 & 5.2 & 20.7 & 9.8\end{array}$

$-12.5$

I.C.

19.3

13.6

8.0

Galactosan

$\begin{array}{lrrrr}\text { mean } & 1.3 & 5.7 & \mathbf{- 5 0 . 8} & 1.0 \\ \text { I.C. } & 3.5 & 10.6 & 16.9 & 14.7\end{array}$

4.7

$\begin{array}{rrrr}11.2 & -13.3 & 8.4 & \mathbf{2 7 . 6} \\ 11.3 & 11.5 & 16.5 & 7.5\end{array}$

Arabitol

mean

$\begin{array}{lll}-0.1 & \mathbf{- 1 9 . 6} & 8.8 \\ & & \end{array}$

4.6

2.3

I.C.

$\begin{array}{lll}3.9 & 9.5 & 14.0\end{array}$

11.3

5.9

Glucose

mean

$\begin{array}{lll}-4.9 & 17.1 & \mathbf{- 4 0 . 3} \\ 3.6 & 11.0 & 18.8\end{array}$

10.5

20.2

$-30.0$

I.C.

18.8

14.8

10.2

17.2

Mannitol

mean

$\begin{array}{lll}4.5 & -4.2 \quad-8.0\end{array}$

$-1.4$

50.9

I.C.

$11.2 \quad 6.7$

14.4

13.7

10.1

Figure 1. Levoglucosan concentration values measured for each sample by ten laboratories: stars are the mean concentrations and bars the standard deviation calculated on all non-outlier measurements.

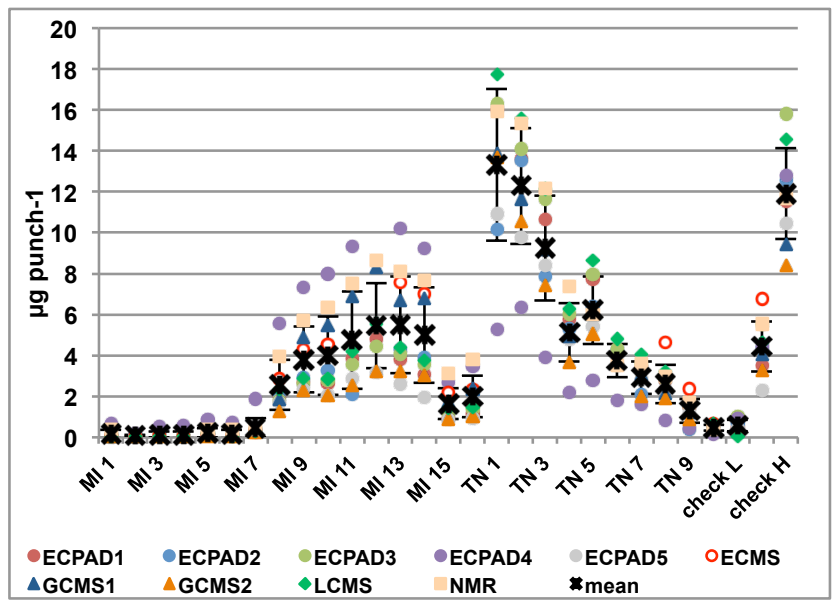


Figure 2. Mannosan concentration values measured for each sample by seven laboratories: stars are the mean concentrations and bars the standard deviation calculated on all non-outlier measurements.

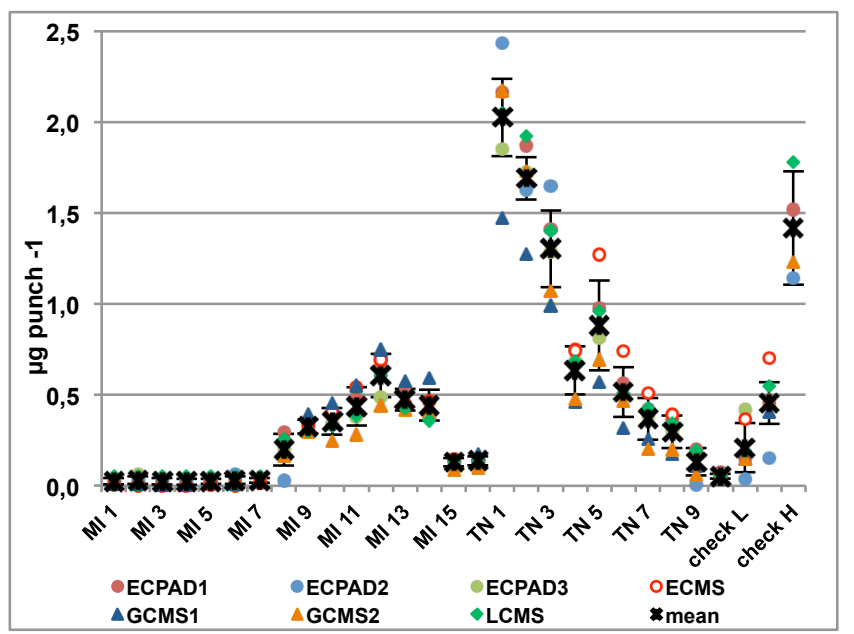

Figure 3. Galactosan concentration values measured for each sample by seven laboratories: stars are the mean concentrations and bars the standard deviation calculated on all non-outlier measurements.

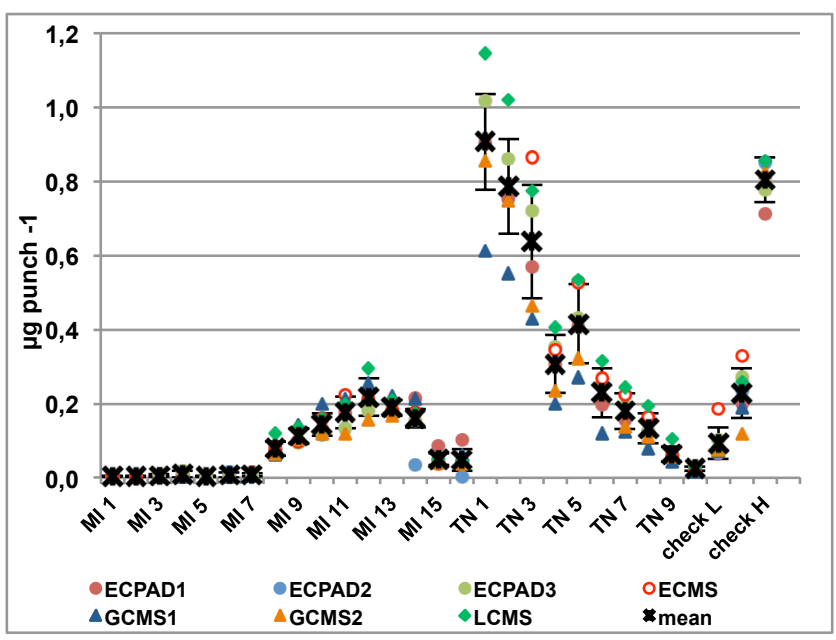


Figure 4. PC2 vs. PC1 biplot of the results of PCA analysis performed on the accuracy of the six analyzed sugars. Blue segments: loadings, i.e. laboratories; red points grouped in ellipses: scores, i.e., sugars.

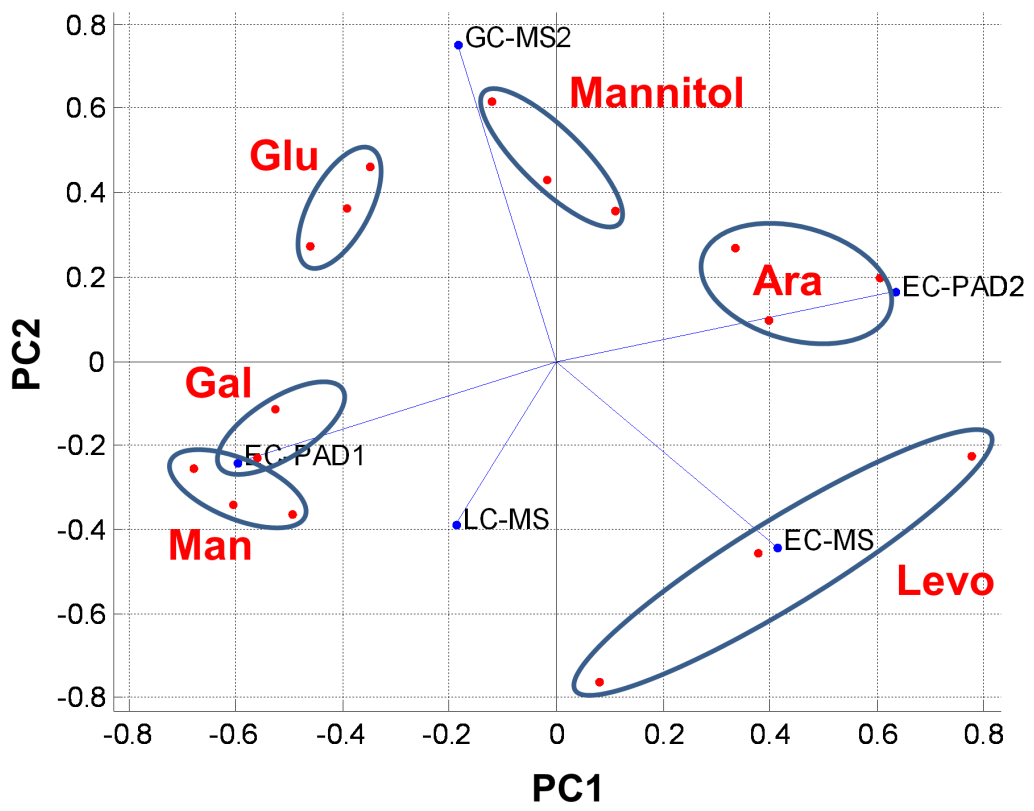

721

722

723

724

725 